\section{Kidney \\ Blood Pressure Research}

\title{
Clinical Manifestation, Management and Prognosis of Acute Myocardial Infarction in Autosomal Dominant Polycystic Kidney Disease
}

\author{
Bo Yang Qi Wang Rui Wang Tao Xu \\ Department of Urology, Peking University People's Hospital, Beijing, China
}

\section{Key Words}

Autosomal dominant polycystic kidney disease (ADPKD) • Acute myocardial infarction (AMI) • Cardiovascular complications

\begin{abstract}
Background/Aims: Cardiovascular complications are the most common cause of death in individuals with autosomal dominant polycystic kidney disease (ADPKD), yet there is no substantial data concerning the clinical characteristics of acute myocardial infarction (AMI) in this population. This study thus aimed to investigate AMI in persons with ADPKD. Methods: A retrospective analysis of ADPKD patients admitted to our hospital over a 13 year period was conducted. Age and gender-matched control patients without ADPKD were also selected at a ratio of 1: 10. Results: A total of 52 ADPKD and 520 non-ADPKD patients were enrolled in the present study, with those in the former group exhibiting significantly poorer kidney function. The distribution of AMI types differed significantly between these two groups. The incidence of ST-segment elevation myocardial infarction (STEMI) was higher $(75.0 \%)$ and the incidence of non-ST segment elevation myocardial infarction (NSTEMI) was lower (25.0\%) in the ADPKD group. At the onset of AMI, sudden cardiac death (SCD) was more common in ADPKD patients (11.5\% vs. $4.6 \%)$. In terms of risk factors, the occurrence of hypertension was greater in ADPKD patients (78.8\% vs. $39.6 \%)$. With regard to subsequent management, ADPKD patients had a higher prevalence of triple-branch coronary lesions (21.1\% vs. $11.2 \%)$, undergoing more coronary artery bypass grafting (CABG) $(7.7 \%$ vs. $5.4 \%)$ and fewer percutaneous coronary interventions $(\mathrm{PCl})(73.1 \%$ vs. $84.6 \%)$. Overall, ADPKD patients had higher rates of mortality (13.5\% vs. 6.2\%). Conclusion: ADPKD patients with AMI suffer from more severe conditions and difficult therapies, resulting in a poorer prognosis.




\section{Kidney Blood Pressure Research}

Yang et al.: Clinical Features of AMI in ADPKD

\section{Introduction}

Autosomal dominant polycystic kidney disease (ADPKD) is the most common hereditary kidney disease [1], with a prevalence of $1 / 1000$ to $1 / 400$ [2]. Patients often present with bilateral renal cysts as they grow older. These renal cysts grow over time, gradually degrading renal structure and function. Even when appropriate treatment is applied, end-stage renal disease (ESRD) still eventually develops in about half of ADPKD patients by the age of 60 [3]. Because of an increased incidence of early-onset hypertension, left ventricular hypertrophy and valvular abnormalities, cardiovascular complications are the most common cause of death in the ADPKD population [4]. Recent data have demonstrated that the frequencies of acute myocardial infarction (AMI) in ADPKD patients from America and Taiwan were up to $6 \%$ and $2.91 \%$ respectively $[5,6]$. To the best of our knowledge, there has been no published study to date regarding the clinical manifestations, management, and prognosis of AMI in patients with ADPKD. We therefore conducted a retrospective analysis of the clinical characteristics of ADPKD patients with AMI and compared these findings to a non-ADPKD population based on a single-center review of 13 years' worth of clinical data.

\section{Materials and Methods}

\section{Data sources and study population}

We retrospectively analyzed ADPKD patients with AMI admitted to Peking University People's Hospital from January 2004 through December 2016. We searched the patient database for ADPKD patients between 18 and 75 years of age, who had been diagnosed with AMI and underwent subsequent treatment in our hospital. Additionally, age- and gender-matched non-ADPKD patients with AMI were included as a control group at a 1:10 ratio. Exclusion criteria were: patients with severe infections, pulmonary diseases, active immune diseases, or advanced malignant tumors. The definition of hypertension was a systolic pressure $\geq$ $140 \mathrm{mmHg}$ and/or a diastolic pressure $\geq 90 \mathrm{mmHg}$. Chronic kidney disease was defined as kidney damage or glomerular filtration rate (GFR) $<60 \mathrm{ml} / \mathrm{min} / 1.73 \mathrm{~m}^{2}$ for 3 months or more, irrespective of cause. CKD classification was as follows: CKD 1 indicated GFR $\geq 90 \mathrm{ml} / \mathrm{min} / 1.73 \mathrm{~m}^{2}$; CKD 2 indicated GFR $60-89 \mathrm{ml} /$ $\mathrm{min} / 1.73 \mathrm{~m}^{2}$; CKD 3 indicated GFR $30-59 \mathrm{ml} / \mathrm{min} / 1.73 \mathrm{~m}^{2}$; CKD 4 indicated GFR $15-29 \mathrm{ml} / \mathrm{min} / 1.73 \mathrm{~m}^{2}$; CKD 5 indicated GFR $<15 \mathrm{ml} / \mathrm{min} / 1.73 \mathrm{~m}^{2}$ or dialysis. In this study, dialysis patients were separated from CKD 5 patients for statistical analyses.

\section{Statistical analysis}

All analyses were conducted using SPSS version 16. All measured data are presented as mean \pm standard deviation. Enumerated data are presented as percentages. Differences in measurement data were compared using an independent $t$-test, while differences in enumerated data were assessed via the Chisquared test or Fisher's exact test. A P-value 0.05 was considered being statistically significant.

\section{Results}

Clinical features and risk factors

A total of 52 patients with ADPKD and 520 patients without ADPKD were eligible for our study (Table 1). The study group and the control group had a male to female ratio of $3: 1$, with mean ages of $49.2 \pm 13.5$ and $51.1 \pm 12.6$ years in the ADPKD and control groups, respectively. Difference in gender and age were not significant between groups. All patients were Asian. Among the ADPKD patients, 39 (75.0\%) were diagnosed with ST-segment elevation myocardial infarction (STEMI) and 13 (25.0\%) were diagnosed with non-ST segment elevation myocardial infarction (NSTEMI), while 308 (59.2\%) were STEMI and $212(40.8 \%)$ were NSTEMI in the control group. The distribution of STEMI and NSTEMI diagnoses was statistically different between these groups $(p=0.026)$.At the onset of AMI, 


\section{Kidney \\ Blood Pressure Research}

ADPKD patients were more likely to suffer sudden cardiac death (SCD) than were controls $(11.5 \%$ vs. $4.6 \%, p=0.033)$. An analysis of cardiovascular risk factors revealed that ADPKD patients had a significantly increased prevalence of hypertension $(78.8 \%$ vs. $39.6 \%$, $\mathrm{p}<0.001$ ). In contrast, non-ADPKD patients were significantly more likely to have a history of smoking and were more likely to be obese $(53.8 \%$ vs. $69.0 \%, 26.9 \%$ vs. $33.1 \%$, $p=0.026$, 0.001 , respectively). Patients with ADPKD had significantly poorer renal function than did non-ADPKD controls $(\mathrm{p}<0.001) .41$ patients in the ADPKD group had hypertension, while 206 patients in the control group had hypertension. Detailed information regarding patient antihypertensive treatments is listed in Table 2.

\section{Management and prognosis}

Patients all underwent coronary artery angiography to identify the culprit vessel, with the exception of 10 ADPKD patients and 52 non-ADPKD patients, who either did not have the opportunity to undergo examination or refused further examination. The coronary angiography findings indicated that ADPKD patients had higher rates of multiple-branch artery lesions, particularly triple-branch lesions $(21.2 \%$ vs. $11.2 \%, p=0.012)$. Operative treatments were performed on the majority of patients, including percutaneous coronary intervention (PCI) and coronary artery bypass grafting (CABG). ADPKD patients underwent CABG significantly more often and PCI significantly less often than did non-ADPKD patients ( $7.7 \%$ vs. $5.4 \%, 73.1 \%$ vs. $84.6 \%, p=0.007,0.032$, respectively). There were also significant differences in the application of subsequent therapies during convalescence in intensive care units (ICU) . A significantly higher percentage of patients with ADPKD underwent continuous renal replacement therapy (CRRT) and temporary pacemaker therapy than did non-ADPKD controls $(13.5 \%$ vs. $2.5 \%, 7.7 \%$ vs. $1.0 \%, p<0.001,0.005$, respectively). Importantly, patients with ADPKD had significantly higher mortality rates than did non-ADPKD patients (13.5\% vs. $6.2 \%, \mathrm{p}=0.046)$. We followed all patients for one additional year, and found that during that time the occurrence of cardiac adverse events, such as new-onset acute coronary syndrome (ACS), heart failure, arrhythmia or SCD, were similar between these two groups (Table 3).

Table 1. Clinical features and AMI risk factors. * indicates a statistically significant difference

\begin{tabular}{lcccccc}
\hline & \multicolumn{7}{c}{ ADPKD } & \multicolumn{2}{c}{ Non-ADPKD } & & \\
Parameter & (N=52) & (N=520) & $\chi^{2}$ & P-value \\
& $\mathrm{N}$ & $\%$ & $\mathrm{~N}$ & $\%$ & & \\
\hline AMI & & & & & 4.926 & $0.026^{*}$ \\
STEMI & 39 & 75.0 & 308 & 59.2 & & \\
NSTEMI & 13 & 25.0 & 212 & 40.8 & & \\
Symptom & & & & & & \\
SCD & & & & & & \\
Cardiogenic shock & 6 & 11.5 & 24 & 4.6 & 4.559 & $0.033^{*}$ \\
& 12 & 23.1 & 76 & 14.6 & 2.600 & 0.107 \\
Risk factors & & & & & & \\
$\quad$ Hypertension & & & & & & \\
Diabetes mellitus & 41 & 78.8 & 206 & 39.6 & 46.944 & $<0.001^{*}$ \\
Hyperlipemia & 10 & 19.2 & 41 & 7.9 & 2.442 & 0.118 \\
History of smoking & 11 & 21.2 & 92 & 17.7 & 0.878 & 0.349 \\
Obesity & 28 & 53.8 & 359 & 69.0 & 4.986 & $0.026^{*}$ \\
Family history of coronary heart disease (CHD) & 14 & 26.9 & 172 & 33.1 & 11.014 & $0.001^{*}$ \\
& 18 & 34.6 & 104 & 20.0 & 3.424 & 0.064 \\
Renal function & & & & & & \\
$\quad$ Normal & & & & & 78.079 & $<0.001^{*}$ \\
CKD 1 & 27 & 51.9 & 477 & 91.7 & & \\
CKD 2 & 11 & 21.1 & 21 & 4.0 & & \\
CKD 3 & 5 & 9.6 & 10 & 1.9 & & \\
CKD 4 & 4 & 7.7 & 3 & 0.6 & & \\
CKD 5 & 1 & 1.9 & 1 & 0.2 & & \\
Dialysis & 2 & 3.8 & 2 & 0.4 & & \\
\hline
\end{tabular}

Table 2. Antihypertensive therapy. ACEI: angiotensin-converting enzyme inhibitors; ARB: angiotensin receptor antagonist; CCB: calcium channel blocker; FDC: fixed-dose combination

\begin{tabular}{|c|c|c|c|c|c|c|c|c|c|c|c|}
\hline \multirow{3}{*}{ Parameter } & \multicolumn{6}{|c|}{ Numbers of antihypertensive drugs } & \multicolumn{5}{|c|}{ Kinds of antihypertensive drugs } \\
\hline & \multicolumn{2}{|c|}{$0-1$} & \multicolumn{2}{|c|}{$2-3$} & \multicolumn{2}{|c|}{$>3$} & \multirow[t]{2}{*}{ ACEI/ARB } & \multirow[t]{2}{*}{ ССВ } & \multirow[t]{2}{*}{ diuretic } & \multirow[t]{2}{*}{$\alpha / \beta$-blocker } & \multirow[t]{2}{*}{ FDC } \\
\hline & $\mathrm{N}$ & $\%$ & $\mathrm{~N}$ & $\%$ & $\mathrm{~N}$ & $\%$ & & & & & \\
\hline ADPKD $(\mathrm{N}=41)$ & 9 & 22.0 & 28 & 68.3 & 4 & 9.8 & 32 & 27 & 25 & 11 & 5 \\
\hline Non-ADPKD $(\mathrm{N}=206)$ & 105 & 51.0 & 89 & 43.2 & 12 & 5.8 & 128 & 131 & 45 & 27 & 28 \\
\hline
\end{tabular}




\section{Kidney Blood Pressure Research}

\section{Discussion}

ADPKD is the most common inherited renal disease. Two genes (PKD1 and PKD2) have been implicated in its development [7]. The disease is characterized by both renal and extra-renal involvement with cystic and non-cystic manifestations. Cardiovascular complications have emerged as a major cause of death in patients with ADPKD [3]. Hypertension occurs in 50-70\% of patients [8] and manifests at a much earlier age than it does in the general population [9]. $50 \%$ of hypertensive patients with ADPKD exhibit left ventricular hypertrophy (LVH) [10]. Additionally, cardiac valvular abnormalities occur in more than $20 \%$ of patients, with defects of the aortic root, annulus, and mitral valve being the predominant irregularities [11]. As one of the most serious complications of ADPKD, AMI must be a topic of greater research focus as it is a cause of mortality in approximately $10 \%$ of the world population [12]. Previous articles have reported that patients with ADPKD have higher AMI rates than do those without ADPKD [5, 6]. Fick et al. [13] investigated the causes of mortality in ADPKD patients based on autopsy data and found that 81\% of ADPKD patients had history of coronary artery disease, with moderate to severe arteriosclerosis commonly found in the aorta. To the best of our knowledge, there has not been substantial clinical research concerning AMI in ADPKD patients. We therefore compiled the clinical information available from our hospital in order to complete a retrospective single center analysis of this important medical topic.

In our study, patients with ADPKD suffered from more serious heart conditions than did non-ADPKD controls. ADPKD affected patients had a higher incidence of both STEMI $(75.0 \%$ vs. $59.2 \%)$ and SCD (11.5\% vs. $4.6 \%)$, indicating that the myocardium in these patients suffered more severe injury and associated necrosis. As a consequence, these individuals were subject to a poorer prognosis and a lower quality of life. Li et al. [14] have recently reported that in 2011 the median age of STEMI onset is 65 years old (55-74 years old) in China in the population at-large. The age at which AMI first appeared was earlier in those with ADPKD. This finding may be attributable to the higher prevalence and earlier onset of hypertension and LVH in ADPKD patients. A significant correlation between hypertension and LVH has been demonstrated in those with ADPKD [15]. Since LVH was a powerful independent risk factor for cardiovascular morbidity and mortality, it may also be a predictor of AMI severity in ADPKD patients. In addition, disrupted renal function and structural damage may also drive AMI in those with ADPKD. In our study, ADPKD patients had, on average, significantly poorer kidney function and a higher percentage of ESRD. Although there has been some evidence indicating that renin-angiotensin-aldosterone system (RAAS) blockade may be effective for the treatment of LVH, vascular remodeling, and renal endothelial dysfunction in ADPKD patients [16], death from AMI always remains unpredictable and difficult to prevent.
Table 3. AMI Management and prognosis. * indicates a statistically significant difference

\begin{tabular}{|c|c|c|c|c|c|c|}
\hline \multirow[t]{2}{*}{ Parameter } & \multicolumn{2}{|c|}{$\begin{array}{l}\text { ADPKD } \\
(\mathrm{N}=52)\end{array}$} & \multicolumn{2}{|c|}{$\begin{array}{c}\text { Non-ADPKD } \\
(\mathrm{N}=520)\end{array}$} & \multirow[t]{2}{*}{$\chi^{2}$} & \multirow[t]{2}{*}{ P-value } \\
\hline & $\mathrm{N}$ & $\%$ & $\mathrm{~N}$ & $\%$ & & \\
\hline \multicolumn{7}{|l|}{ Culprit vessel } \\
\hline Anterior descending branch & 11 & 21.2 & 178 & 34.2 & 2.318 & 0.128 \\
\hline Left circumflex branch & 2 & 3.8 & 48 & 9.2 & & 0.413 \\
\hline Right coronary artery & 3 & 5.8 & 72 & 13.8 & & 0.177 \\
\hline Two branches & 15 & 28.8 & 112 & 21.5 & 2.861 & 0.091 \\
\hline Three branches & 11 & 21.2 & 58 & 11.2 & 6.271 & $0.012^{*}$ \\
\hline \multicolumn{7}{|l|}{ Therapy } \\
\hline PCI & 38 & 73.1 & 440 & 84.6 & 4.583 & $0.032^{*}$ \\
\hline CABG & 4 & 7.7 & 28 & 5.4 & & $0.007^{*}$ \\
\hline Thrombolysis & 3 & 5.8 & 15 & 2.9 & & 0.212 \\
\hline Conservative treatment & 7 & 13.5 & 37 & 7.1 & 3.045 & 0.081 \\
\hline \multicolumn{7}{|l|}{ Supportive treatment } \\
\hline Intra-aortic balloon pump (IABP) & 5 & 9.6 & 24 & 4.6 & 2.285 & 0.131 \\
\hline Mechanical ventilation & 4 & 7.7 & 18 & 3.5 & & 0.130 \\
\hline CRRT & 7 & 13.5 & 13 & 2.5 & 16.603 & $<0.001^{*}$ \\
\hline Temporary pacemaker & 4 & 7.7 & 5 & 1.0 & & $0.005^{*}$ \\
\hline Cardiac function (Killip classification) & & & & & 3.845 & 0.279 \\
\hline I & 32 & 61.5 & 382 & 73.5 & & \\
\hline II & 13 & 25.0 & 98 & 18.8 & & \\
\hline III & 4 & 7.7 & 21 & 4.0 & & \\
\hline IV & 3 & 5.8 & 19 & 3.7 & & \\
\hline Mortality & 7 & 13.5 & 32 & 6.2 & 3.973 & $0.046^{*}$ \\
\hline Cardiac adverse events & 4 & 7.7 & 19 & 3.7 & & 0.147 \\
\hline
\end{tabular}




\section{Kidney Blood Pressure Research}

Among the analyzed AMI risk factors, there was a higher incidence of hypertension in ADPKD patients (78.8\% vs. 39.6\%), whereas rates of smoking and obesity were higher in those without ADPKD (53.8\% vs. $69.0 \%$, 26.9\% vs. 33.1\%, respectively). Blood pressure levels are elevated on average by $4-6 \mathrm{mmHg}$ in pediatric patients with ADPKD as compared to unaffected age and gender matched controls [17]. The average age of hypertension onset is 30-34 years in these individuals, with men being more commonly affected than women [18]. Hypertension contributes not only to an increased incidence of cardiovascular mortality but also to faster ESRD progression, which is itself an independent risk factor for AMI [19]. Previous studies have reported that the most effective therapy for ADPKD patients is the control of hypertension via RAAS inhibition [20]. However, a meta-analysis by Xue et al. [21] recently demonstrated that there is little evidence to indicate that different antihypertensive treatments alter ADPKD kidney disease progression. Furthermore, only rigorous blood pressure control is likely to be associated with any measurable decline in left ventricular mass index (LVMI) [16]. There is a clear need for additional studies regarding the management of blood pressure in ADPKD patients.

Coronary artery angiography was performed on 42 ADPKD and 468 non-ADPKD patients, revealing that multiple-branch lesions, especially triple-vessel lesions, occurred more frequently in ADPKD patients $(21.2 \%$ vs. $11.2 \%)$. Beyond hypertension, other metabolic abnormalities have also been reported to occur more frequently in ADPKD patients relative to a healthy control population, resulting in coronary artery disease [22]. Several articles have reported that ADPKD patients exhibit an increased incidence of posttransplant diabetes mellitus or new-onset diabetes after transplantation [23-25], indicating that an increased diabetogenic state arises due to ADPKD itself. HLA-B27 has been reported to be a potential risk factor for post-transplant diabetes mellitus in those with ADPKD [26]. ADPKD patients with diabetes mellitus have larger renal volumes, earlier age of hypertension diagnosis and an increased risk of early death as compared to those patients with ADPKD alone [27], and cardiovascular disease has been shown to be a dominate cause of death in ADPKD patients with diabetes [28]. Additionally, insulin resistance is often observed in ADPKD patients and is significantly associated with LVMI [29]. Abnormal lipid metabolism can drive a deterioration of renal function in ADPKD patients, thereby contributing to AMI progression. An inverse correlation between serum high-density lipoprotein levels and both the rate of kidney growth and the decline in glomerular filtration rate has been observed in ADPKD patients [30]. Furthermore, several clinical studies have demonstrated that oxidative modification of low-density lipoprotein in patients with early stage ADPKD can drive the deterioration of renal function and hypertension [31, 32]. Consequently, ADPKD patients exhibit more severe coronary lesions and more frequently undergo CABG. Similarly, patients with ADPKD had greater rate of CRRT (13.5\% vs. 2.5\%) and temporary pacemaker therapy (7.7\% vs. $1.0 \%)$ after a heart attack. As a result, the rate of AMI-associated mortality was significantly higher in ADPKD patients (13.5\% vs. $6.2 \%)$.

\section{Conclusion}

Cardiovascular complications are common and have emerged as a major cause of death in ADPKD patients. ADPKD patients with AMI suffer from more severe condition and difficult therapies, resulting in a poorer prognosis. Due to the prevalence of AMI in ADPKD patients, early diagnosis and clinical intervention are recommended to improve patient outcomes.

\section{Disclosure Statement}

The authors declare they have no conflict of interest. 


\section{Kidney \\ Blood Pressure Research}

\begin{tabular}{l}
\hline Kidney Blood Press Res 2018;43:1806-1812 \\
\hline \begin{tabular}{l|l} 
DOI: 10.1159/000495638 & $\begin{array}{l}\text { @ 2018 The Author(s). Published by S. Karger AG, Basel } \\
\text { www.karger.com/kbr }\end{array}$ \\
\hline Publisned ontIne: T December 2018
\end{tabular}
\end{tabular}

Yang et al.: Clinical Features of AMI in ADPKD

\section{References}

1 Torres VE, Harris PC, Pirson Y: Autosomal dominant polycystic kidney disease. Lancet 2007;369:12871301.

2 Torres VE, Harris PC: Autosomal dominant polycystic kidney disease: the last 3 years. Kidney Int 2009;76:149-168.

-3 Perrone RD, Ruthazer R, Terrin NC: Survival after end-stage renal disease in autosomal dominant polycystic kidney disease: contribution of extrarenal complications to mortality. Am J Kidney Dis 2002;39:660.

4 Perrone RD, Malek AM, Watnick T: Vascular complications in autosomal dominant polycystic kidney disease. Nat Rev Nephrol 2015;11:589-598.

-5 Helal I, Berenice R, Mettler P, Mc Fann K, Tkachenko O, Yan X, Schrier RW: Prevalence of cardiovascular events in patients with autosomal dominant polycystic kidney disease. Am J Nephrol 2012;36:362-370.

6 Sung P, Chiang H, Yang Y, Chen C, Chiang JY, Yip H: An association between autosomal-dominant polycystic kidney disease and the risk of acute myocardial infarction in Asian population- results of a nationwide study. Oncotarget 2017;8:19365-19375.

7 Ecder T, Schrier RW: Cardiovascular abnormalities in autosomal-dominant polycystic kidney disease. Nat Rev Nephrol 2009;5:221-228.

-8 Ecder T, Schrier RW: Hypertension in autosomal-dominant polycystic kidney disease: early occurrence and unique aspects. J Am Soc Nephrol 2001;12:194-200.

-9 Kelleher CL, Mc-Fann KK, Johnson AM, Schrier RW: Characteristics of hypertension in young adults with autosomal dominant polycystic kidney disease compared with the general U.S. population. Am J Hypertens 2004;17:1029-1034.

10 Chapman AA: Left ventricular hypertrophy in autosomal dominant polycystic kidney disease. J Am Soc Nephrol 1997;8:1292-1297.

11 Lumiaho A, Lkheimo R, Miettinen R, Niemitukia L, Laitinen T, Rantala A, Lampainen E, Laakso M, Hartikainen J: Mitral valve prolapse and mitral regurgitation are common in patients with polycystic kidney disease type 1. Am J Kidney Dis 2001;38:1208-1216.

12 Fokkema ML, James SK, Albertsson P, Akerbolom A, Calais F, Eriksson P, Jensen J, Nilsson T, Smet BJ, Sjogren I, Thorvinger B, Lagerqvist B: Population trends in percutaneous coronary intervention: 20-year results from the SCAAR (Swedish Coronary Angiography and Angooplasty Registry). J Am Coll Cardiol 2013;61:1222-1230.

13 Fick GM Johnson AM, Hammond WS, Gabow PA: Causes of death in autosomal dominant polycystic kidney disease. J Am Soc Nephrol 1995;5:2048-2056.

14 Li J, Wang Q, Hu S, Wang Y, Masoudi F, Spertus JA, Krumholz HM, Jiang L: ST-segment elevation myocardial infarction in China from 2001 to 2011 (the China PEACE-Retrospective Acute Myocardial Infarction Study): a retrospective analysis of hospital data. Lancet 2015;385:441-451.

15 Bardaji A, Martinez-Vea A, Valero,A, Gutierrez C, Garcia C, Ridao C, Oliver JA, Richart C: Cardiac involvement in autosomal dominant polycystic kidney disease: a hypertensive heart disease. Clin Nephrol 2002;56:211220.

-16 Torres VE, Abebe KZ, Chapman AB, Schrier RW, Braun WE, Steinman TI, Winklhofer FT, Brosnahan G, Czarnecki PG, Hogan MC, Miskulin DC, Rahbari-Oskoui FF, Grantham JJ, Harris PC, Flessner MF, Moore CG, Perrone RD: Angiotensin blockade in late autosomal dominant polycystic kidney disease. N Engl J Med 2014;371:2267-2276.

17 Rizk D, Jurkovitz C, Veledar E, Bagby S, Baumgarten DA, Rahbari-Oskoui F, Steinman T, Chapman AB: Quality of life in autosomal dominant polycystic kidney disease patients not yet on dialysis. Clin J Am Soc Nephrol 2009;4:560-566.

18 Chapman AB, Guay-Woodford LM, Grantham JJ, Torres VE, Bae KT, Baumgarten DA, Kenney PJ, King BF, Glockner JF Wetzel LH, Brummer ME, Robbin ML, Bennett WM, Klahr S, Hirschman GH, Kimmel PL, Thompson PA, Miller JP: Renal structure in early autosomal-dominant polycystic kidney disease (ADPKD): The Consortium for Radiologic Imaging Studies of Polycystic Kidney Disease (CRISP) cohort. Kidney Int 2003;64:1035-1045. 


\section{Kidney \\ Blood Pressure Research}

\begin{tabular}{l}
\hline Kidney Blood Press Res 2018;43:1806-1812 \\
\hline \begin{tabular}{l|l} 
DOI: 10.1159/000495638 & $\begin{array}{l}\text { @ 2018 The Author(s). Published by S. Karger AG, Basel } \\
\text { www.karger.com/kbr }\end{array}$ \\
\hline Publisned online: T December 2018
\end{tabular}
\end{tabular}

Yang et al.: Clinical Features of AMI in ADPKD

19 Gabow PA, Johnson AM, Kaehny WD, Kimberling WJ, Lezotte DC, Duley IT, Jones RH: Factors affecting the progression of renal disease in autosomal-dominant polycystic kidney disease. Kidney Int 1992;41:13111319.

20 Patch C, Charlton J, Roderick PJ, Gulliford MC: Use of antihypertensive medications and mortality of patients with autosomal dominant polycystic kidney disease: a population-based study. Am J Kidney Dis 2011;57:856-862.

21 Xue C, Zhou C, Dai B, Yu S, Xu C, Mao Z, Chen D, Zhao X, Wu J, Chen W, Mei C: Antihypertensive treatment in adult autosomal dominant polycystic kidney disease: network meta-analysis of the randomized controlled trials. Oncotarget 2015;6:42515-42529.

-22 Pietzak-Nowacka M, Safranow K, Byra E, Binczak-Kuleta A, Cjechanowicz A, Ciechanowski K: Metabolic syndrome components in patients with autosomal dominant polycystic kidney disease. Kidney Blood Press Res 2009;32:405-410.

23 De Mattos AM, Olyaei AJ, Prather JC, Golconda MS, Barry JM, Norman DJ: Autosomal-dominant polycystic kidney disease as a risk factor for diabetes mellitus following renal transplantation. Kidney Int 2005;67:714-720.

24 Hamer RA, Chow CL, Ong AC, McKane WS: Polycystic kidney disease is a risk factor for new-onset diabetes after transplantation. Transplantation 2007;83:36-40.

25 Caillard S, Eprinchard L, Perrin P, Laura B, Francoise H, Moreau, Kessler L, Moulin B: Incidence and risk factors of glucose metabolism disorders in kidney transplant recipients: role of systematic screening by oral glucose tolerance test. Transplantation 2011;91:757-764.

26 Pietrzak-Nowacka M, Safranow K, Nowosiad M, Debska-Slizien A, Dziewanowski K, Glyda M, Jankowska M, Rutkowski B, Ciechanowski K: HLA-B27 is a potential risk factor for posttransplantation diabetes mellitus in autosomal dominant polycystic kidney disease patients. Transplant Proc 2010;42:3465-3470.

-27 Reed B, Helal I, McFann K, Wang W, Yan X, Schrier RW: The impact of type II diabetes mellitus in patients with autosomal dominant polycystic kidney disease. Nephrol Dial Transplant 2012;27:2862-2865.

28 Backenroth R, Popovtzer MM: Does type 2 diabetes mellitus delay renal failure in autosomal dominant polycystic kidney disease? Kidney Int 2002;24:803-813.

-29 Lumiaho A, Pihlajamaki J, Hartikainen J, Ikaheimo R, Miettinen R, Niemitukia L, Lampainen E, Laakso M: Insulin resistance is related to left ventricular hypertrophy in patients with polycystic kidney disease type 1. Am J Kidney Dis 2003;41:1219-1224.

-30 Torres VE, Grantham JJ, Chapman AB, Mrug M, Bae KT, King BF, Wetzel LH, Martin D, Lockhart ME, Bennett WM, Moxey-Mims M, Abebe KZ, Lin Y, Bost JE: Potentially modifiable factors affecting the progression of autosomal dominant polycystic kidney disease. Clin J Am Soc Nephrol 2011;6:640-647.

31 Wang D, Standgaard S, Borresen ML, Luo Z, Connors SG, Yan Q, Wilcox CS: Asymmetric dimethylarginine and lipid peroxidation products in early autosomal dominant polycystic kidney disease. Am J Kidney Dis 2008;51:184-191.

32 Brookes ZL, Ruff L, Upadhyay VS, Huang L, Prasad S, Solanky T, Nauli SM, Ong AC: Pkd2 mesenteric vessels exhibit a primary defect in endothelium-dependent vasodilatation restored by rosiglitazone. Am J Physiol Heart Circ Physiol 2013;304:H33. 